\title{
Index selection of Kazakh karakul sur-type sheep with platinum shades
}

\author{
MUKHIT DYUSEGALIYEV, UTENBERGEN BISENOV, \\ AYMAN NURGALIYEVA, ELMIRA ADIETOVA
}

\begin{abstract}
Department of Biology and Agricultural Disciplines, Atyrau State University.
\end{abstract} H. Dosmukhamedov Ave., Student 212, Atyrau, Kazakhstan

\section{Dyusegaliyev M., Bisenov U., Nurgaliyeva A., Adietova E. Index selection of Kazakh karakul sur-type sheep with platinum shades \\ Summary}

Karakul sheep farming is one of the effective subsectors of animal breeding in the south-western region of Kazakhstan. Sheep coloring is a result of genetic factors. Breeding can provide farmers with offspring of the desired color through the selection of parental couples. This research introduces an index method for breeding sur-type sheep with the proportion of underfur fibers under $25 \%$. Such a proportion of underfur fibers provides a $\mathbf{1 5 . 2 5 \%}$ deeper color within the breed at the $25.3 \%$ higher chance of getting platinum shades. Platinum coloring in sheep makes them less piebald. The inheritance index is quite stable and is within 55.66$\mathbf{6 5 . 6 6 \%}$. In the breeding flock, the initial proportion of sur-type lambs which could be used in coat making (elite class) was up to $\mathbf{8 . 7 2 \%}$. The analysis of platinum color heritability by Kazakh sur-type karakul sheep shows that this color is inherited as a dominant one in the line breeding. The share of sur-type sheep with platinum shades was between $85.85 \%$ and $87.27 \%$. The difference in the inherited trait between the groups of sheep selected according to the proportion of underfur fibers was insignificant, $0.99-1.42 \%(P>0.05)$. The stabilizing selection introduced into the theory of line breeding of Kazakh sur-type sheep allowed optimizing the variability of selected features to the level of desired parameters. The authors have proposed the index selection method for sur-type sheep breeding that can be applied to improve the Atyrau sheep flock, to increase their genetic potential, and to apply various line breeding levels to accelerate the breeding process. The originally designed method for improving breeding indexes will be useful when setting optimal breeding goals (fur color and quality) and assessing genetic parameters of a certain sheep flock. The study was approved by the Ethics Committee attached to the Far Eastern State Agrarian University (Protocol No. 5 of 25 May 2010).

Keywords: breeding, index selection method, fibers, selection

Karakul sheep farming is a result of organizational and breeding activities carried out to develop arid and semiarid areas (1). Other livestock industries are no match for karakul sheep farming when it comes to product diversity (11). Karakul sheep have high endurance and are well adapted to grazing in desert and semi-desert conditions. Adult animals have an elongated head, a Roman type nose, and long hanging ears. The body is big enough, with strong bones and relatively high limbs. A fat-rumped wide tail ends with an S-shaped finial. The uterus of karakul sheep weighs from 45 to $50 \mathrm{~kg}$. Males generally have well-developed horns, while the females are usually hornless (13).

Karakuls can have black, gray, sur (golden brown), white, pink and colored coats $(12,15,16)$. The sur- type color is the most original and elegant color that a karakul can have. The sur-colored two- to threeday-old lambs have unevenly pigmented curls. They have a dark base, which may be black, reddish brown and $\tan$, with silvery white or golden yellow top fur $(15,16)$.

Sheep coloring is a result of genetic factors. Breeding can provide farmers with offspring of a desired color through the selection of parental couples.

The direction of this research was selected with regard to the following prevailing problems that exist in the karakul sheep farming of Kazakhstan. These problems include:

- a high demand for karakul pelts with original colors on foreign and domestic fur markets; 
- extremely low adaptation of Surkhandarya surtype sheep from Uzbekistan to the conditions of Western Kazakhstan;

- lack of breeding achievements in this field (14).

The issue in current line breeding is the further improvement of selection methods and techniques to enhance breeding and qualities of the original flock.

What is currently important about line breeding is that methods and techniques of selection must be improved so that they can enhance breeding and fixation of the main selected traits of the original flock. The range of traits includes color brightness and evenness over the entire surface of pelts; long and medium, narrow semicircular curls; strong and normal silkiness and luster of wool, and other economically useful fur quality indices (1). If sur-type sheep are bred without any coloring, then the resulting sheep will be with poor-quality fur not vivid in color. Traditional methods for assessing karakul lamb fur coloration imply visual assessment of their coat pigmentation. These methods provide subjective results in large-scale selection (17). Hence there is an urgent need to improve selection by using modern methods for estimating the value of breeding. These modern methods include calculation of complex selection indices. In this context, this research is targeted at developing a selection index geared towards underfur fibers. The fur-corrected selection index will allow breeding karakul sur-type sheep with platinum shades.

The purpose of this research is to develop a selection index to select sheep with platinum shades of fur for line breeding and to study the platinum color heritability in Kazakh sur sheep.

\section{Material and methods}

The Ethics Committee attached to the Far Eastern State Agrarian University (Protocol No. 5 of 25 May 2010) approved the study.

The selection program to create a flock of Kazakh karakul sheep of original colors was performed in two stages:

Stage I - a selection index is introduced to enhance the genetic potential of sur-type sheep.

Stage II - color inheritance across the flock is studied; line breeding of varying degrees is used to speed up the breeding process.

Study areas. The study was carried out in a basic farm enterprise of the Western Kazakhstan. The research period was from 1998 to 2010 .

Data. This research was carried out on the karakul surtype sheep with platinum shades living in the Republic of Kazakhstan.

Tab. 1. Platinum-colored lambs, distribution by the proportion of underfur fibers

\begin{tabular}{|l|c|c|c|c|c|c|c|c|c|}
\hline \multicolumn{1}{|c|}{ Indicator } & $\begin{array}{c}\text { No. of } \\
\text { lambs }\end{array}$ & \multicolumn{9}{|c|}{ Selection index value } \\
& 37 & 38 & 39 & 40 & 41 & 42 & 43 & 44 \\
\hline Frequency of occurrence, lambs & 32 & 1 & 2 & 5 & 8 & 6 & 6 & 3 & 1 \\
Lambs with selected trait to 100 lambs, \% & 100 & 3.1 & 6.2 & 15.6 & 25.0 & 18.8 & 18.8 & 9.4 & 3.1 \\
\hline
\end{tabular}

(half-brother $\times$ half-sister) -83 females, $6.25 \%$ (uncle $\times$ nephew) -86 females, $3.25 \%$ (cousin $\times$ cousin) -346 females. The breeding progress is shown in Figure 2.

Research methods. The offspring were distributed into classes individually according to the Guide to karakul Classing. The following characteristics of the newborn karakul lambs were identified. The 


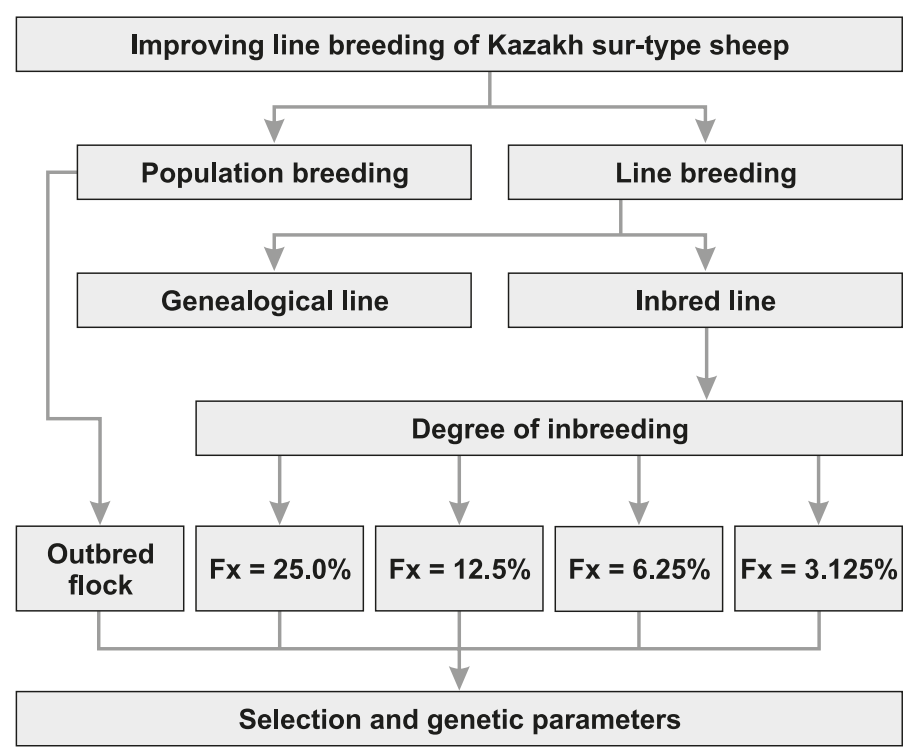

Fig. 2. The line breeding of karakul sur-type sheep

length of fibers on the rump was measured in mm using a millimeter ruler. The length and width of curls on the rump were measured in mm using the same ruler. The sheepskin area was measured in $\mathrm{mm}$ by multiplying the length of a sheepskin by its width. The wool was weighted using a dial scale "Gometer" within the accuracy of $5 \mathrm{~g}$. The pelt thickness was measured on the rump using a thickness gauge "Textilmash" within the accuracy of $0.1 \mathrm{~mm}$. The shine and silkiness of wool were determined visually (3).

Animal growth and development were studied by taking the live weight and linear body measurements: at birth, at the age of 4-4.5 and 12 months. The results of measurements were used to calculate the selection index.

Samples of 60-70 g wool were washed in a solution of xylene, then rinsed in distilled water, and put into $96 \%$ and $70 \%$ alcohol. At the end, fibers were dried to constant weight on the filter paper. The line breeding coefficient was calculated according to Kravchenko (5).

The wool-producing ability of sheep was determined by cutting off fibers at different ages during the spring and autumn shearing. The wool length was measured according to methodology published by the All-Russia Research Institute for Animal Husbandry (VIZh).

Data analysis. Data were entered into Origin 9.1. The analysis was performed using STATA 12.0 (StataCorp LP, USA). The prevalence of platinum coloring was determined using the $95 \%$ confidence interval, $\mathrm{P} \leq 0.05$.

\section{Results and discussion}

The index selection of Kazakh karakul sheep. The authors have carried out studies to determine the proportion of underfur fibers in selected sheep (Tab. 2). The study of platinum-colored rams shows the proportion of underfur fibers at the level between $36 \%$ and $44 \%$ of the total number of fibers in the coat.

The frequency of occurrence of platinum-colored lambs with high
Tab. 2. Platinum-colored rams selected for breeding, grouped by the proportion of underfur fibers

\begin{tabular}{|l|c|c|}
\hline \multicolumn{1}{|c|}{ Selection index value, $\%$} & $\begin{array}{c}\text { No. of } \\
\text { rams }\end{array}$ & $\begin{array}{c}\text { Frequency of } \\
\text { occurrence, } \%\end{array}$ \\
\hline High proportion of underfur fibers, $\geq 42 \%$ & 10 & 31.25 \\
\hline Average proportion of underfur fibers, $40-41 \%$ & 14 & 43.75 \\
\hline Low proportion of underfur fibers, $\leq 39 \%$ & 8 & 25.0 \\
\hline Total across groups & 32 & 100.0 \\
\hline
\end{tabular}

Tab. 3. Characteristics of rams: mean measurements and variation

\begin{tabular}{|l|c|r|c|}
\hline \multicolumn{1}{|c|}{ Characteristic } & Measurements & \multicolumn{1}{c|}{$\delta$} & \multicolumn{1}{c|}{$\mathrm{C}_{\mathrm{v}}$} \\
\hline Straight fiber length, $\mathrm{mm}$ & $12.8 \pm 0.27$ & 1.52 & 11.93 \\
\hline Curl length, mm & $46.4 \pm 1.80$ & 10.18 & 21.94 \\
\hline Curl width, $\mathrm{mm}$ & $9.6 \pm 0.27$ & 1.53 & 15.91 \\
Curliness, \% & $67.4 \pm 2.60$ & 14.71 & 21.82 \\
Live weight, $\mathrm{kg}$ & $4.2 \pm 0.08$ & 0.45 & 10.78 \\
\hline
\end{tabular}

proportion of underfur fibers was $31.25 \%$ (10 lambs), with an average proportion of underfur fibers $-43.75 \%$ (14 lambs), with low proportion of underfur fibers $25 \%$ (8 lambs).

Table 3 shows the mean measurements and the variation of characteristics found in selected rams.

Platinum color heritability in Kazakh sur-type sheep (line breeding). Second generation offspring included $1.9 \%$ higher number of lambs with platinum shades; $2.2 \%$ higher number of lambs with bronze shades; $2.1 \%$ higher number of lambs with amber shades; and 2.2\% higher number of anthracite shades, $\mathrm{P}>0.05$. These lambs were also larger in size by $4.5 \%$. The difference between second generation karakuls and the purebred karakuls was as follows: difference in platinum coloration $-34.7 \%$; in bronze coloration $-32.7 \%$; in amber coloration $-34.8 \%$; in anthracite coloration $-30.3 \%, \mathrm{P}<0.001$. The difference in curl size varies between lambs born from rams of different colors: from platinum rams $-30.8 \%$, from bronze rams $-29.1 \%$, from amber rams $-31 \%$, from anthracite rams $-26.6 \%, \mathrm{P}<0.001$.

The analysis of color heritability in karakul sur-type sheep shows that in line breeding, the inheritance of coloration is stable (Tab. 4). In line breeding, platinum color inheritance was $85.85 \%-87.27 \%$. The difference

Tab. 4. Platinum color inheritance in karakul sur-type sheep, in \%

\begin{tabular}{|l|c|c|c|c|c|}
\hline $\begin{array}{l}\text { Rams grouped by the } \\
\text { proportion of underfur } \\
\text { fibers (PoUFF) }\end{array}$ & $\begin{array}{c}\text { No. of } \\
\text { rams }\end{array}$ & platinum & $\begin{array}{c}\text { bolors } \\
\text { bronze }\end{array}$ & amber & Others \\
\hline $\begin{array}{l}\text { Group I } \\
\text { PoUFF } \geq 42 \%\end{array}$ & 106 & $34.94 \pm 4.63$ & $5.66 \pm 2.24$ & $4.72 \pm 2.06$ & $54.72 \pm 4.83$ \\
$\begin{array}{l}\text { Group II } \\
\text { PoUFF = 40-41\% }\end{array}$ & 102 & $59.86 \pm 4.85$ & $4.90 \pm 2.14$ & $2.94 \pm 1.67$ & $32.36 \pm 4.63$ \\
$\begin{array}{l}\text { Group III } \\
\text { PoUFF } \leq 39 \%\end{array}$ & 110 & $87.27 \pm 3.18$ & $4.55 \pm 1.98$ & $4.54 \pm 1.98$ & $3.64 \pm 1.78$ \\
\hline \begin{tabular}{l} 
Total across groups \\
\hline
\end{tabular} & 318 & $61.00 \pm 1.92$ & $5.03 \pm 1.22$ & $4.40 \pm 1.15$ & $4.09 \pm 1.11$ \\
\hline
\end{tabular}


in the inherited trait between groups was insignificant $0.99-1.42 \%(\mathrm{P}>0.05)$. From this one can assume that the PoUFF index is not sensitive to the level of platinum color inheritance. Therefore, breeding can be conducted within all groups.

Platinum color inheritance. Table 5 shows that platinum color is inherited stably. The share of sur-type sheep with platinum shades was between $85.85 \%$ and $87.27 \%$ (CI: $11.55-13.97$ ).

Table 6 shows that inherited color distributes across the coat with evenness, which is also stably inherited. The share of sur-type sheep with even coloration was between $66.04 \%$ and $87.27 \%$ (CI: 14.35-27.44). The highest level of inheritance $(87.27 \%)$ was observed in the third group. It was $8.84 \%$ higher than in the second group, where it was $78.43 \%$, and $21.23 \%$ higher than in the first group, where it was $66.04 \%, \mathrm{P}>0.05$.

In the third group, the share of offspring with uneven coloration or gradually pigmented offspring was low. Color evenness characterizes the distribution of color across the lamb's body (6).

As can be seen from Table 7, coloration is inherited at the high level, which varies between $3.21 \%$ and $79.0 \%$ (CI: $13.05-20.36$ ). The highest level of inheritance $(79.0 \%)$ was observed in the third group. It was $7.43 \%$ higher than in the second group, where it was $71.57 \%$, and $15.77 \%$ higher than in the first group, $\mathrm{P}>0.05$.

Coloration was investigated in those lambs that had the selection index value under average. According to Baibekov, the proportion of guard hairs in gray lambs was $36.5 \%$. In line breeds, this figure grows up to $40.7 \%$. With age, the proportion of guard hairs increases by $2-6 \%$ (2).

At this point, grey karakuls have homozygosis for a dominant feature (4). Therefore, breeding can be carried out in all groups. Nechifor discovered that some karakul sheep have a share of $2 \%$ of a different color. This fact confirms that the black color is given by two different genotypes; namely dominant black and recessive black, and that these genotypes differ from each other by the fact that the recessive one favors the occurrence of other colors, often brown and grey (9).

Nel observed that karakul sheep with grey-brown fibers usually bear dark-grey lambs (10). It should be noted that studies of sur color genetics remain openended. The earlier studies found that the degree of pigmentation to some extent depends on the value of the wool fineness $(7,8)$.

The advantage of this technique is that it allows for successfully breeding early-maturing Edilbay and Kazakh fat-tailed sheep of original colors, with coarse fur, as well as karakul sheep (Surkhandarya and Karakalpak sur-types). This technique also allows for improving the genetic potential of karakul sheep
Tab. 5. Inherited proportion of underfur fibers

\begin{tabular}{|l|c|c|c|c|}
\hline $\begin{array}{l}\text { Rams grouped by the } \\
\text { proportion of underfur } \\
\text { fibers (PoUFF) }\end{array}$ & $\begin{array}{c}\text { No. of } \\
\text { rams }\end{array}$ & \multicolumn{3}{|c|}{ Distribution of lambs in a new generation* } \\
\hline $\begin{array}{l}\text { Group I } \\
\text { PoUFF } \geq 42 \%\end{array}$ & 106 & $55.66 \pm 4.82$ & $29.25 \pm 4.42$ & $15.09 \pm 3.47$ \\
$\begin{array}{l}\text { Group II } \\
\text { PoUFF = 40-41\% }\end{array}$ & 102 & $17.65 \pm 3.17$ & $65.68 \pm 4.70$ & $16.67 \pm 3.69$ \\
$\begin{array}{l}\text { Group III } \\
\text { PoUFF } \leq 39 \%\end{array}$ & 110 & $11.82 \pm 3.08$ & $30.00 \pm 4.36$ & $58.18 \pm 4.70$ \\
\hline
\end{tabular}

Explanation: *intra-bred lambs with different proportion of underfur fibers (high, average and low)

Tab. 6. Inherited color evenness

\begin{tabular}{|c|c|c|c|}
\hline \multirow{2}{*}{$\begin{array}{l}\text { Rams grouped by the } \\
\text { proportion of underfur } \\
\text { fibers (PoUFF) }\end{array}$} & \multirow{2}{*}{$\begin{array}{l}\text { No. of } \\
\text { rams }\end{array}$} & \multicolumn{2}{|r|}{ Color evenness } \\
\hline & & even & uneven, gradual pigmentation \\
\hline $\begin{array}{l}\text { Group I } \\
\text { PoUfF } \geq 42 \%\end{array}$ & 106 & $66.04 \pm 4.60$ & $33.96 \pm 4.06$ \\
\hline $\begin{array}{l}\text { Group II } \\
\text { PoUFF = 40-41\% }\end{array}$ & 102 & $78.43 \pm 4.07$ & $21.57 \pm 4.07$ \\
\hline $\begin{array}{l}\text { Group III } \\
\text { PoUFF } \leq 39 \%\end{array}$ & 110 & $87.27 \pm 3.18$ & $12.73 \pm 3.18$ \\
\hline Total across groups & 318 & $77.36 \pm 2.35$ & $22.64 \pm 2.35$ \\
\hline
\end{tabular}

Tab. 7. Inherited coloring, contours

\begin{tabular}{|l|c|c|c|}
\hline \multicolumn{1}{|c|}{$\begin{array}{c}\text { Rams grouped by the } \\
\text { proportion of underfur } \\
\text { fibers (PoUFF) }\end{array}$} & $\begin{array}{c}\text { No. of } \\
\text { rams }\end{array}$ & $\begin{array}{c}|c| \\
\text { strong boundaries } \\
\text { between two colors }\end{array}$ & $\begin{array}{c}\text { weak boundaries } \\
\text { between two colors }\end{array}$ \\
\hline $\begin{array}{l}\text { Group I } \\
\text { PoUFF } \geq 42 \%\end{array}$ & 106 & $63.21 \pm 4.68$ & $36.79 \pm 4.68$ \\
\hline $\begin{array}{l}\text { Group II } \\
\text { PoUFF = 40-41\% }\end{array}$ & 102 & $71.57 \pm 4.46$ & $28.43 \pm 4.46$ \\
\hline $\begin{array}{l}\text { Group III } \\
\text { PoUFF } \leq 39 \%\end{array}$ & 110 & $79.09 \pm 3.88$ & $20.91 \pm 3.88$ \\
\hline Total across groups & 318 & $71.38 \pm 2.53$ & $28.62 \pm 2.53$ \\
\hline
\end{tabular}

on live weight, precocity and adaptive capacity. This will help to shorten the breeding time.

This study was about breeding karakul sur-type sheep of leading colors to form highly productive flocks of sheep of desirable types. The following conclusions can be stated:

1. In line breeding, platinum color is inherited at the level between $47 \%$ and $52 \%$.

2 . An index method was developed for breeding surtype sheep with the proportion of underfur fibers under $25 \%$. Such a proportion of underfur fibers provides a $15.25 \%$ deeper color within the breed at the $25.3 \%$ higher chance of getting platinum shades. Platinum coloring in sheep makes them less piebald. The inheritance index is quite stable and is within 55.66-65.66\%. In the breeding flock, the initial proportion of sur-type lambs, which could be used in coat making (elite class), was up to $8.72 \%$.

The originally designed method for improving breeding indexes will be useful when setting optimal 
breeding goals (fur color and quality) and assessing genetic parameters of sheep flock.

\section{References}

1. Asylbekov B. Zh., Zhumadulaeva A. I., Yermekbaeva R. Zh., Makhatova I. M., Aidarbekova $S$. K.: Experience in a Breeding Program to Create a Flock of Sur Karakul Sheep of the New Surkhan Darya Type. Rus. Agric. Sci. 2014 40, 282-284, https://doi.org/10.3103/S106836741404003X.

2. Baibekov E.: Using the exact method of assessing the degree of hair lightening during selection. Achievements in Karakul Breeding. Kaynar Publishers, Alma-Ata 1987.

3. Dyachkov I. N., Zakirov M. D., Pismennaya R. T.: Methodic of studying the quality of karakul. Collection of scientific works. Samarkand 1963, 13, 105-119.

4. Hrincă Gh.: Investigations concerning the polymorphism of blood group structures in the botoşani karakul breed in relation to the color varieties of sheep. P. Romanian Acad. Series B 2017, 19, 39-50, https://acad.ro/sectii2002/ proceedingsChemistry/doc2017-1/art06.pdf.

5. Kravchenko N. A.: Genetic theory of selection, selection and methods of breeding animals. Science, Novosibirsk 1976.

6. Lebedev A. I.: The experience in breeding Karakul Sur-type sheep of platinum color on the farm "Farish". Dissertation, Samarqand 1971.

7. Lundie R. S.: Coat Colour Genetics of the Damara Sheep, [in:] The Damara of Southern Africa, Ed. du Toit D, Prieska 2007, p. 38-122.

8. Lundie R. S.: The genetics of colour in fat-tailed sheep: a review. Trop. Anim. Health Prod. 2011, 43, 1245-1265.

9. Nechifor I., Pascal C., Florea M.: The Color Transmission in the Case of Cross Breed Sheep Belonging to the Black Karakul Variety. J. Anim. Sci. Biotechno. 2015, 72, 199-202, https://doi.org/10.15835/buasvmcn-asb:11331.
10. Nel J. A., van Wyk J. B.: Colour inheritance and the significance of colour variation in Karakul pelt production. Karakul 1982. Karakul Breeders Society of Southern Africa. Windhoek 1982.

11. Robinson S., Milner-Gulland E. J., Alimaev I.: Rangeland degradation in Kazakhstan during the Soviet era: re-examining the evidence. J. Arid. Environ. 2003, 53, 419-439, https://doi.org/10.1006/jare.2002.1047.

12. Safonov V.: Assessment of Heavy Metals in Milk Produced by Black-and-White Holstein Cows from Moscow. Curr. Res. Nutr. Food Sci. 2020, 8, 1-7, https:// doi.org/10.12944/CRNFSJ.8.2.06.

13. Sharma N. K., Sharma M. K., Gahlot G. C.: Comparative performance of Marwari and Karakul sheep in Arid zone: growth. Vet. Pract. 2017, 18, 111-112.

14. Turganbaev R. U.: Length of hair of astrakhan of Karakal Pakstan. South Asian Academic Research Journals 2017, 7, 9.

15. Ukbaev Kh. I., Dyusgaliev M. Zh.: Methods for breeding karakul Sur-type sheep. Journal of Agricultural Science of Kazakhstan 2008, 10, 41.

16. Ukbaev Kh. I., Shamekenova R. D.: Color inheritance in Atyrau fat-tailed sheep raised for wool and meat. Journal of Agricultural Science of Kazakhstan 2008, $5,9-11$.

17. Vsevolodov E. B., Latypov I. F., Sarsekeyeva G. Zh., Tusupova R. M., Musayeva A. S., Alibayev N. N., Lakhanova K. M., Ochilov K. L.: Guide to an instrument assessment of color of the Karakul lambs. Nurly Beine, Shymkent 2009.

18. Wright S.: Coefficients of inbreeding and relationship. Am. Nat. 1922, 56, 330-338

Corresponding author: Dr. Mukhit Dyusegaliyev, Atyrau State University, H. Dosmukhamedov Ave., Student 212, Atyrau, Kazakhstan; e-mail: muhitdusegaliev@gmail.com 